\title{
HY8778
}

\section{Cross-Flow Turbine Design for Energy Production and Discharge Regulation}

\author{
Vincenzo Sammartano ${ }^{1}$, Costanza Aricò $^{2}$, Marco Sinagra $^{3}$ and Tullio Tucciarelli ${ }^{4}$ \\ ${ }^{1}$ Department of Civil, Environmental, Aerospace, Materials Engineering, Università degli Studi di Palermo, Viale delle \\ Scienze, 90128 Palermo, Italy; email: vincenzo.sammartano@unipa.it; \\ ${ }^{2}$ Department of Civil, Environmental, Aerospace, Materials Engineering, Università degli Studi di Palermo, Viale delle \\ Scienze, 90128 Palermo, Italy; email: costanza.arico@unipa.it \\ ${ }^{3}$ Department of Civil, Environmental, Aerospace, Materials Engineering, Università degli Studi di Palermo, Viale delle \\ Scienze, 90128 Palermo, Italy; email: marco.sinagra@unipa.it \\ ${ }^{4}$ Department of Civil, Environmental, Aerospace, Materials Engineering, Università degli Studi di Palermo, Viale delle \\ Scienze, 90128 Palermo, Italy; email: tullio.tucciarelli@unipa.it
}

\section{ABSTRACT}

Cross-flow turbines are very efficient and cheap turbines that allow a very good cost/benefit ratio for energy production located at the end of conduits carrying water from a water source to a tank. In this paper a new design procedure for a cross-flow turbine working with a variable flow rate is proposed. The regulation of the head immediately upstream the turbine is faced by adopting a shaped semicircular segment moving around the impeller. The maximum efficiency of the turbine is attained by setting the velocity of the particles entering the impeller at about twice the velocity of the rotating system at the impeller inlet. If energy losses along the pipe are negligible, the semicircular segment allows always a constant hydraulic head and a constant velocity at the impeller inlet, even with variable flow rate. The decrease of the turbine efficiency along with the inlet surface reduction is first investigated; a design methodology, using also CFD simulations, is then proposed for both the cases of negligible and not negligible energy losses along the pipe.

Keywords: Turbines; Energy production, CFD, water supply network.

\section{INTRODUCTION}

Hydroelectric has been for more than a century the major source of energy and is, still 
now, the major source of renewable energy worldwide (Zimny et al. 2013). The number of new large hydro-plants per year is at present undergoing a strong reduction, due to an increased social sensitivity to the river ecological and transport equilibrium, which leaves a very limited number of sites available for new large hydro-plant construction. On the other hand, the on-going transformation of the centralized system of energy production and transportation into a more flexible distributed system (smart grids) has given a strong input to the construction of pico and micro hydro-energy production devices (from few to $1000 \mathrm{~kW}$ ) (Khurana and Kumar 2011). This type of turbine can be easily installed: 1) along small rivers, where it is possible to transform the potential hydraulic energy dissipated along a short reach between two river sections in electricity, without diverting the minimum flow rate required to maintain the ecological equilibrium therein; 2) at the end of a water pipe delivering the water from a main source (spring, water well, natural or artificial basin) to a tank serving a city water district; 3) at the end of a sewer pipe delivering the treated waste water to its final receiving water body.

The authors define the total efficiency as the ratio between the output power of the turbine and the power of the flow passing through the upper inlet of the hydroelectric plant, measured with respect to the level of the turbine axis. This inlet is a river section in case 1) and a pipe section in cases 2) and 3). The total efficiency $\eta_{t}$ can be estimated as:

$$
\eta_{t}=\frac{P_{o u t}}{\gamma \cdot Q \cdot H_{t}}
$$

where $P_{\text {out }}$ is the output power, $Q$ is the discharge and $H_{t}$ is the topographic jump between the inlet location and the turbine axis (see Fig. 1). Unless the source is an artificial basin and discharge regulation is carried out from the same hydraulic plant where the turbine is located, the discharge delivered to the turbine changes according to the river level or to the spring natural flow (see Fig.1). 
The efficiency of the turbine is defined as:

$$
\eta=\frac{P_{o u t}}{\gamma Q \cdot\left(H_{c}-H_{c, o}\right)}
$$

where the hydraulic head $H_{c}$ immediately before the turbine depends on its characteristic curve (Fig. 2), unless a specific head regulation system is installed inside the machine. The hydraulic head $H_{c, o}$ at the turbine outlet, measured with respect to the axis of the turbine, is usually negligible in both the real plants and in the tested prototype with respect to the inlet head $H_{c}$. Observe that $H_{c}$ will be different from the level $H$ computed by the following curve of pipe energy losses:

$$
H_{t}-H=K_{1} \cdot Q^{2}
$$

where $K_{l}$ depends on the pipe size and material (in many cases energy losses along the pipe can be neglected, so this means that $H=H_{t}$ ). This implies that, if no dissipation valves are installed along the pipe, the pipe section will be only partially filled up by the water for some extension after the inlet. In this part of the pipe a free surface flow will occur, with abrupt transformation in pressurized flow at the intersection between the pipe and the energy line.

For the previous reasons, the turbine efficiency $\eta$ and the hydraulic head $H_{c}$ can be much lower than, respectively, $\eta_{\max }$ and $H_{t}$, far from the optimal discharge value (where $\eta_{\max }$ is the maximum machine efficiency). Because the output power of the turbine is given by:

$$
P_{\text {out }}=\eta(Q) \cdot \gamma \cdot Q \cdot H_{c}(Q)
$$

this implies a strong reduction with respect to the nominal power $P_{n o m}=\gamma Q H_{t}$. Moreover, if the manager of the water supply network want to avoid any free flow condition inside the pipe, the mechanical energy corresponding to the head difference $H-H_{c}$ must be dissipated by an extra valve that has to be installed along the pipe.

This inconvenience can be avoided by the use of a discharge regulator inside the turbine. An optimum regulator should allow the turbine characteristic curve and the curve of the pipe 
energy losses to match each other and this should guarantee the efficiency $\eta$ to remain always close to the maximum efficiency value $\eta_{\max }$. If pipe energy losses are negligible, this is equivalent to keeping a constant $H_{c}=H$ hydraulic head for all the possible discharge values.

The documentation provided by the turbines manufacturers, usually, includes the characteristic curve (for one or many possible regulation conditions) and the efficiency curve, as defined in Eq. (2). Not much information is available on the dissipation occurring in the regulation system, strongly affecting the total efficiency, as defined in Eq. (1). A good efficiency (as defined in Eq. 2) under variable operating conditions can be attained with two different approaches: hydraulic and electrical regulation.

The hydraulic regulation, often more flexible and efficient than the electrical one (Carravetta et al. 2013), depends on the type of turbine: needle stroke for Pelton turbines, adjustable guide vanes for Francis turbine, fixed or adjustable guide vanes or adjustable runner blades for Diagonal or Kaplan turbine (Paish 2002; Singh 2009). Pelton turbines can have multiple needles, which can be set in on/off position according to the available discharge. The reverse pumps have no regulation system, so in order to obtain a flexibility of the turbine related to the variability of discharge and/or head drop, hydraulic regulation has to be done with a series/parallel hydraulic circuit (Carravetta et al. 2012, 2014; Carravetta and Giugni 2006). This circuit consists of a by-pass conduit and of a pressure reducing valve in series with the turbine.

Recent power electronic devices allow the regulation of electrical voltage and frequency in order to vary the generator speed (Joshi et al. 2005; Ramuz et al. 2005). When turbines are coupled with asynchronous generators, as it happens in most of the hydroelectric power plants, the electronic regulation allows an almost constant ratio between the inlet particle velocity and the impeller rotational speed, for different discharge values. This leads also to a 
constant efficiency, because efficiency is mainly related to the above mentioned velocity ratio, but has little effect on the turbine characteristic curve and $H_{c}$ can be much smaller than the available head $H$.

The cost of the regulation system is of course a central issue. Adjustable runner blades or guide vanes have a cost which is usually proportional to their number, which is usually very large $(30 \div 40$ blades), multiple needle strokes for Pelton turbines require also a continuous operation of having the single strokes switched on/off and some of them can remain unused for most of the time. Electronic devises are still very expensive. See in Fig. 3 the efficiency curves of several types of turbines.

\section{THE TRADITIONAL OSSBERGER CROSS-FLOW TURBINE}

The Banki-Michell turbine is a simple and economic turbine appropriate for microhydroelectric plants. The peak efficiency of this turbine is somewhat less than a Kaplan, Francis or Pelton turbine, but its relative efficiency is close to one within a large range, especially above the optimum discharge value.

The Banki-Michell turbine has a drum-shaped runner consisting of two parallel discs connected together near their rims by a series of curved blades (see Fig. 4). The turbine has an horizontal rotational shaft, unlike Pelton and Turgo turbines, which can have either horizontal or vertical shaft orientation. The water flow enters through the cylinder defined by the two disk circumferences (also called impeller inlet) and it crosses twice the channels confined by each blade couple. After entering the impeller through a channel, the particle leaves it through another one. Going through the impeller twice provides additional efficiency. When the water leaves the runner, it also helps to clean the runner of small debris and pollution. So the cross-flow turbines get cleaned as the water leaves the runner (small sand particles, grass, leaves, etc. get washed away), preventing energy losses. Other turbine 
types get clogged easily, and consequently face power losses despite higher nominal efficiencies. The edges of the blades are sharpened to reduce resistance to the flow of water and the blades are welded to the disks.

A design methodology for the standard Banki-Michell turbine has been recently proposed by Sammartano et al. (2013). The most important parameter for the turbine efficiency is the angle $\alpha$ between the fluid particles trajectories along the circumference of the impeller inlet and the tangent to the same circumference. The optimal efficiency is obtained when the shape of the nozzle allows a constant velocity norm $V$ along the impeller inlet and a very small $\alpha$ value. The lower limit for $\alpha$ is given by the need to limit the impeller width and by the additional resistance caused by the consequent small channel cross-sectional area existing between each couple of blades. The optimal efficiency is obtained for a ratio between the inlet particle velocity and the machine rotating velocity equal to approximately two. The efficiency drops slowly for larger ratios and more quickly for lower ratios, up to a theoretical zero value for a ratio equal to one.

The Banki-Michell turbine is often called cross-flow, due to the special geometry of its impeller, or also Ossberger, from the name of the industry that carries on its production since 1933. The efficiency of the traditional Ossberger cross-flow turbine is well documented in the case of constant discharge. See for example the historical overview of cross flow turbine described in Khosrowpanah et al. (1984).

In the Ossberger cross-flow turbine the hydraulic head can be regulated by using an hydraulic flap that is easily installed into the nozzle upstream the impeller. In this system the flap is rotated around its axis according to the actual discharge, as it is simply shown in the same Fig. 4, with the aim to reduce the inlet cross-sectional area and to keep an inlet velocity norm close to the optimal value. On the other hand it is easy to recognize that the flap leads to: 1) a local fluid particle deceleration inside the nozzle downstream the flap, and a 
corresponding energy losses, 2) an irregular velocity distribution along the impeller inlet, leading to a departure from the optimal norm and direction of the inlet velocities. The result is a relatively poor efficiency curve, especially for partially closed positions of the hydraulic flap.

Experimental and numerical studies (Costa Pereira and Borges 1996; Kokubu et al. 2011) show that the use of hydraulic flap inside the nozzle could increase the efficiency of the turbine for given discharge, but this device cannot be used to guarantee the available $H$ at the turbine inlet. Other researchers tried to improve the efficiency of the cross-flow by inserting some kind of guide inside the impeller (Kokubu et al. 2011; Haurissa et al. 2012) or adding a draft tube to redesign the shape of the guide vanes (Kaniecki 2012).

The Czech engineer Miroslav Cink introduced a further development of the cross-flow radial turbine. This cross-flow turbine has a circular profiled segment for inflow regulation (see Fig. 5). The main difference between the Cink and the original Ossberger systems is that in the first one the fluid particles immediately enter the impeller after the restriction given by the circular segment, without any preliminary deceleration, and exchange their energy with the impeller. There are no particular information about the fluid-dynamic efficiency of the turbine, based on experiments or CFD analysis, but the Cink regulation system seems the most promising one for the goal of achieving high total efficiency values, because it provides a variable reduction of the impeller inlet surface, without any additional dissipation inside the nozzle. Moreover, it will be shown in the next sections that its design fits quite well with the cross-flow design recently proposed by Sammartano et al. (2013).

\section{ENERGY TRANSFER OPTIMIZATION}

The relationship between the hydraulic head immediately before the turbine and the norm $\mathrm{V}$ of the inlet velocity is given by: 


$$
V=c_{i n} \sqrt{2 g H_{c}}
$$

where $c_{i n}$ is a coefficient that would be exactly one if the pressure along the inlet circumference were exactly zero, along with the energy losses inside the nozzle.

The actual $c_{\text {in }}$ can be estimated "a posteriori" by running simulations where the hydraulic head $H_{c}$ is given as upstream boundary condition. Preliminary numerical tests suggest that its value changes between 0.75 and 0.85 , according to the actual size of the turbine, but it remains almost constant by changing the impeller inlet closure. This suggests that, assuming a constant value for different segment rotation, both velocity norm $V$ and head $H$ remain constant when the inlet surface area is reduced proportionally to the actual discharge by rotating the circular segment. Using a simple pressure control at the end of the pipe, immediately before the turbine, it is possible to regulate the closure of the inlet area in order to keep constant $H_{c}$ and to get the optimal particle velocity at the inlet.

Sammartano et al. (2013) provided a simple criteria for the design of a cross-flow turbine without head regulation. If the regulation system is embedded in a cross flow turbine designed only for the maximum discharge according to these criteria, and carry on CFD simulations with different impeller inlet closures, the researcher can observe that the efficiency drops along with the closure extension. To better understand the reason of such reduction, the reader need to remind that the energy exchanged between the water particles and each channel of the rotating impeller along a time interval $\Delta t$ is given by the Euler's equation only if all the particle streamlines enter and leave the channel along $\Delta t$. In this case the Euler's equation is written as:

$$
E_{\Delta t}^{c}=\rho \cdot Q_{c} \cdot\left(\underline{V_{1}} \cdot \underline{U_{1}}-\underline{V_{2}} \cdot \underline{U_{2}}\right) \cdot \Delta t
$$

where $\rho$ is the water density, $Q_{c}$ is the discharge entering and leaving the single channel, $\underline{V}_{1}$ and $\underline{V}_{2}$ are the velocities of the particles respectively entering and leaving the channel, $\underline{U}_{1}$ 
and $\underline{U}_{2}$ are the corresponding velocities of the rotating reference system. The energy exchanged inside a single channel along $\Delta t$ is different from the left hand side of Eq. (6) if, along that time, the particle streamlines only partially cover the channel extension, which is the case of channels crossing the beginning or the end of the impeller inlet along $\Delta t$.

For a given blade channel and within a fixed $\Delta t$, three cases can occur: a) within time interval $\Delta t$ fluid particles are entering along all the inlet channel section and are leaving along all the outlet channel section (which is the case of fully developed exchange, when Eq. (6) holds); b) within a $\Delta t$ interval no particles are entering along all the inlet channel section or are leaving along all the outlet channel section (no entering or leaving flux and zero exchanged energy); c) at least for a fraction of $\Delta t$ particles are entering/leaving the blade channel along a part of the channel inlet/outlet section. This case will hold close to the inlet initial and final points (see Fig. 6). To compute the energy exchange in the case c) the authors divide the total flow inside the channel in an infinite number of stream tubes with infinitesimal section, each one with its specific discharge $q$ per unit length and initial and final sections located in the channel (see Fig. 6), but changing along the time. The energy exchanged during time $\Delta t$ in case $\mathrm{c}$ ), according to this simplified scheme, is equal to:

$$
E_{\Delta t}^{c}=\iint_{\Delta t, \Delta L} \rho \cdot q \cdot\left(\underline{V_{I}} \cdot \underline{U_{I}}-\underline{V_{F}} \cdot \underline{U_{F}}\right) \cdot d s d t
$$

where $\Delta L$ is the blade distance measured along the inlet arc, $\underline{V}_{\mathrm{I}}$ and $\underline{U}_{\mathrm{I}}$ are respectively the particle and the reference system velocity at the first section of the stream tube, $\underline{V}_{\mathrm{F}}$ and $\underline{U}_{\mathrm{F}}$ are respectively the particle and the reference system velocity at the final section of the stream tube. $\underline{V}_{I}$ and $\underline{V}_{F}$ are equal to $\underline{V}_{1}$ and $\underline{V}_{2}$ only if the first or the final stream sections are respectively on the inlet or the outlet channel section.

The authors investigate step 1 of the energy transfer, when the flow enters the impeller and most of its energy is exchanged with the same impeller. Observe that, if the last particle of the stream tube is located before the channel outlet section (Fig. 6a), the second scalar 
product in Eq. (7) is greater than the corresponding scalar product in Eq. (6), because of the smaller angle $\beta_{F}$ between $\underline{V}_{\mathrm{F}}$ and $\underline{U}_{\mathrm{F}}$. Also, if the first particle of the streamline is located after the channel inlet section (Fig. 6b), the first scalar product in Eq. (7), for given particle and reference system velocity norm, is smaller than the corresponding scalar product in Eq. (6), because of the larger angle $\beta_{I}$ between $\underline{V}_{\mathrm{I}}$ and $\underline{U}_{\mathrm{I}}$. The integral in Eq. (7) will be, for these reasons, always smaller than the result obtained in case a) and given by the right hand side of Eq. (6).

The efficiency of the overall mechanism will increase, of course, as much as the number of channels falling in case c) is small with respect to the channels falling in case a). To do that, assuming a given rotational speed, it seems important to increase the $\lambda$ angle and to reduce the channel extension by increasing the $D_{2} / D_{1}$ ratio. The effect of the increment of the $D_{2} / D_{1}$ ratio is, for given number of blades, a smaller curvature of the trajectories most internal to the channel with respect to the trajectories of the particles moving close to the blade surface. To avoid this reduction, it is possible to increase the number of blades $N_{\mathrm{b}}$ (and the corresponding channels) and to reduce the thickness of each blade. Because the strains in each blade are proportional to the momentum entering in each channel, the increment of the blade number and the corresponding momentum reduction allows also a reduction of the blade thickness (Verhaart 1983).

\section{VALIDATION OF THE HYDRODYNAMIC ANALYSIS BY MEANS OF CFD NUMERICAL SIMULATIONS}

In order to get a confirmation of the previous hydrodynamic analysis, a set of 2D simulations has been carried out by using the CFX-ANSYS code. Because the implemented software does not allow two-dimensional fluid dynamic simulations, the $2 \mathrm{D}$ problem was solved by generating a mesh extruded to a single layer and by imposing symmetry on the two 
side faces. In the tests the computational domain was divided using both tetrahedral and prismatic elements. The prismatic elements were used to discretize the computational domain inside the near-wall region along the blades and the boundary surfaces, where a boundary layer is present, while the tetrahedral elements were used to discretize the remaining domain. The algorithm used in CFX to create the tetrahedral element discretization is called "Patch Conforming", that is a Delaunay tetra mesher with an advancing-front point insertion technique used for mesh refinement. The prismatic elements were created by using the "Pre Inflation" algorithm, so the surface mesh was inflated first, and then the rest of the volume mesh was generated. The quality of the mesh was verified by using a pre-processing procedure by ANSYS $^{\circledR}$ ICEM CFD ${ }^{\mathrm{TM}}$. Both water and air phases were modelled in the computational domain according to the free surface homogeneous model: according to this model the two fluids share the same dynamic fields of pressure, velocity and turbulence. The computational domain is divided into two sub-domains: the stator (nozzle and casing) has an inertial reference system; the rotor (impeller) has a non-inertial reference system, integral with the rotation axes of the rotor. The domains, made of tetrahedral and prismatic elements, were divided into about 700,000 finite volumes, respectively. One of the meshes used for these simulations is reported in Fig. 7.

In the CFX code, the interface model "general connection" was set, since the reference system changes at the interface of the above mentioned sub-domains. The "transient rotorstator" option was also selected to take into account the transient effects along the above mentioned interface. Using this option, the interface position is updated at each time step, and the relative position of the grids on each side of the interface changes. At the nozzle inlet the volume fractions were set at zero for air and at one for water. At the base of the production chamber, at the water outlet, a pressure value of 1 atm was imposed as downstream boundary condition, enabling the possible flow of air from the outside towards the inside of the 
machine. The same boundary condition was imposed in the nodes along the air vents.

Preliminary numerical simulations allowed to estimate the velocity coefficient $c_{i n}$ used in Eq. (5). In each of these simulations the hydraulic head $H_{c}$ was given as upstream boundary condition along the nozzle inlet area and the inlet velocity $V$ was estimated by the code as the ratio between the discharge and the inlet area. The $c_{i n}$ value is then estimated from both values by Eq. (5). In the following case studies the preliminary tests quickly converge to a $c_{i n}$ coefficient equal to 0.8 and this value remains almost constant also for the other simulations.

The optimal blade design has been tested, in the following case study, for two different positions of the discharge regulator, $\lambda_{\min }=39.8^{\circ}$ and $\lambda_{\text {mod }}=91.7^{\circ}$, corresponding to the optimal inlet velocity of the minimum $\left(Q_{\min }\right)$ and modal discharge $\left(Q_{\text {mod }}\right)$ of the duration curve, that is (Sammartano et al. 2013):

$$
V_{o p t}=c_{i n} \sqrt{2 g H}=\frac{\omega D_{1}}{\cos \alpha}
$$

where $D_{l}$ is the outer impeller diameter that satisfies Eq. (8) and $\omega$ is rotational velocity (see Fig.8).

The unknown blade parameters are the ratio $D_{2} / D_{1}$ and the number of blades $N_{b}$. Seven numbers of blades $N_{b}$ (from 40 to 70 with a step of 5 blades) were investigated, as well as a $D_{2} / D_{1}$ ratio ranging from 0.65 to 0.8 . For each simulation, the efficiency of the cross-flow turbine was calculated as the ratio between the power supplied to the impeller (applied torque $T$ times the impeller angular velocity $\omega$ ) and the power lost by water passing through the turbine (difference between the hydraulic power of the water flow in the inlet and in the outlet of the turbine). The simulations were carried out until steady state conditions were reached (corresponding to a simulation time $T_{s}=1.5 \mathrm{~s}$ with a time step of $0.001 \mathrm{sec}$ ). See in Fig. 9a the efficiencies attained with the optimum $N_{b}=60$ and in Fig. 9b the efficiencies attained with the optimum $D_{2} / D_{1}=0.75$, in the first case of $\lambda=\lambda_{\min }$. The optimum efficiency 
is $85.8 \%$.

Fig. 10 shows the inlet angles, as well as the corresponding efficiencies computed for a large range of possible discharges (according to the optimal velocity given in Eq. (8)), using the optimized blade geometry. Observe that the efficiency is almost constant despite the large variation of the discharge, but has a small positive gradient. The positive gradient is due to the increment of the inlet angle following the discharge increment.

In the second case, with $\lambda=\lambda_{\text {mod }}$, the plots reported in Figs. 11 show the efficiencies obtained for the computed optimal parameters $N_{b}=50$ and $D_{2} / D_{1}=0.65$. The peak efficiency in this second case is $86.9 \%$. This efficiency is a bit higher than the peak efficiency obtained in the first case, and this is consistent with the adopted larger inlet angle. The efficiency curves of the two impellers, designed according to $Q_{\text {min }}$ and $Q_{\text {mod }}\left(\lambda_{\min }\right.$ and $\left.\lambda_{\bmod }\right)$ can be observed in Fig.12. The reader can observe that the efficiency of the impeller designed for the larger inlet angle is a bit higher than the other one only for the larger discharge values. The outcome of this analysis is that, unless very uneven duration curves occur, it is always convenient to perform the blade design according to the minimum occurring inlet angle.

\section{TURBINE DESIGN IN CASE OF NEGLIGIBLE ENERGY LOSSES}

When the energy losses in the upstream pipe are negligible, a variable discharge does not affect the upstream head. Thus, $H_{t} \approx H$ and the turbine designer has to select the best values of the following parameters (see Fig. 8): 1) the $\alpha$ angle between the particle velocity direction and the tangent direction at the impeller inlet, 2) the $\lambda_{\max }$ angle facing the fully opened circular segment, 3 ) the outer impeller diameter $\left.D_{1}, 4\right)$ the inner impeller diameter $D_{2}$ and the $N_{\mathrm{b}}$ blades number. The width $B$ of the impeller, the initial $\beta_{1}$ and final $\beta_{2}$ angles between the blade tangent and the reference system velocity directions, the blade radius $\rho_{b}$, 
as well as the nozzle shape, can be derived according to Sammartano et al. (2013) given the previous parameters. The thickness of the blades can be chosen according to the structural strains computed in preliminary tests. A possible strategy for the choice of the primary parameters 1-4 is the following one:

1) Select $\alpha$. In Sammartano et al. (2013) it has been shown that the optimum $\alpha$ value, according to Euler's equation, is zero, but this value leads to an infinite $B$ impeller width. Other lower limits for $\alpha$ are given by the corresponding high velocity variability along each channel inlet, as well as constructive difficulties in matching the corresponding angles. A largely accepted compromise is $\alpha=15^{\circ}$. According to the observations in section "ENERGY TRANSFER OPTIMIZATION", the $\lambda_{\max }$ impeller inlet angle should be as large as possible to get a constant efficiency for increasing closure values. On the other hand, because the extension of the semicircular segment has to be the same of the impeller inlet (to be able to get a complete closure) it is easy to realize (Fig. 8) that an excessive length would stop the second flow channel crossing, in the case of fully opened segment, with consequent reduction of the produced energy. According to preliminary testing this maximum angle is $120^{\circ}$. The $\omega$ angular velocity of the reference system depends on the number of electrical poles of the asynchronous generator and on the electric network frequency.

2) Select the initial values of $D_{2} / D_{1}$ and $N_{\mathrm{b}}$ according to the values suggested in Sammartano et al. (2013), $D_{2} / D_{1}=0.65$ and $N_{\mathrm{b}}=35$, and set the initial value of the coefficient $c_{\text {in }}=0.85$.

3) Select the outer impeller diameter $D_{1}$ value corresponding to the optimum velocity in Eq. (8), where the norm $V_{\text {opt }}$ of the velocity at the impeller inlet is selected according to Eq. (5). Compute the impeller width $B$ (Fig.7), corresponding to $Q_{\max }$ and $\lambda=\lambda_{\max }$, according to the impeller inlet continuity equation: 


$$
B=\frac{Q_{\text {max }}}{\lambda_{\max } \cdot D_{1} \cdot c_{i n} \sqrt{2 g H} \cdot \sin \alpha}
$$

where $Q_{\max }$ is the maximum water discharge for the given discharge versus time curve $Q(t)$.

The $c_{i n}$ coefficient has to be tested by comparison with the value returning from Eq. (5) using the velocity actually computed by a CFD simulation. If the test is negative, $c_{i n}$ has to be updated according to Eq. (5) and the steps 1-3 have to be repeated until convergence is attained. Along these iterations the impeller parameters $D_{2} / D_{1}$ and $N_{\mathrm{b}}$ remain constant.

4) Optimize the blade geometry $\left(D_{2} / D_{1}\right.$ and $\left.N_{\mathrm{b}}\right)$ according to the minimum inlet angle, $\lambda=\lambda_{\min }$, and the discharge $Q_{\min }$.

Before accepting the estimated optimum geometry, the designer has also verify the feasibility of the corresponding width $B$ computed in Eq. (9). If $B<3-4 \mathrm{~cm}$ the $2 \mathrm{D}$ hypothesis fails, the surface effects of the impeller plates become relevant and a different type of turbine, like Pelton, is likely to be more efficient, unless an increment of the $\omega$ angular velocity is possible, with a consequent reduction of $D_{1}$ and an increment of $B$. If $B$ is very large, several times the external diameter, structural problems arise. Also in this case a different type of turbine, like a Kaplan, could be considered, unless a reduction of the $\omega$ angular velocity is possible. Another option is to use an outer diameter $D_{1}$ less efficient, but larger than the optimal one, in order to reduce $B$ according to Eq. (9). A flowchart representing the design procedure in case of negligible energy losses is reported in Fig. 13.

\section{APPLICATION TO A CASE STUDY}

The following case study investigates the economic benefit of the replacement of a flow control valve with the proposed cross flow turbine in the outlet node of an oversized water pipeline.

The water pipeline "Jato", $40 \mathrm{~km}$ long, supplies municipal water from the drinking water 
plant "Cicala" to the forebay tank, called "Petrazzi", which supplies Palermo town (Italy). The free surface of the upper tank, located at the "Cicala" drinking water plant, has an altitude of $164.3 \mathrm{~m}$ a.m.s.l.. The lower tank, "Petrazzi", has a free surface level at an altitude of $83.9 \mathrm{~m}$ a.m.s.l. The tanks are connected by a cast-iron pipeline with a nominal pipe size DN 1400. In the pipe, near the lower tank, a flow control valve is installed. Fig. 14 shows the monthly mean flow distribution, measured in the year 2010, which can be assumed also unvaried in the next subsequent years. The peak demand attains in the original discharge hydrograph a maximum value of $0.785 \mathrm{~m}^{3} / \mathrm{s}$. In order to maintain an almost constant upper water level, the water manager (AMAP S.p.A.) uses a flow control valve. The opening degrees of the flow control valve are automatically selected according to the measured trend of the upstream pressure and water discharge supplied by the pipeline in the upper tank.

The idea is to replace the flow control valve with a cross flow turbine designed with the procedure described in the previous section. In order to ensure the water demand even in exceptional conditions, the maximum discharge $Q_{\max }$ selected in step 4) of the design procedure is equal to $0.785 \mathrm{~m}^{3} / \mathrm{s}$. The rotational speed $\omega$ has been set to a constant value of 380 r.p.m.. In steps $1-3$ of the design procedure, an outer diameter $D_{1}=735 \mathrm{~mm}$ has been computed.

The width $B$ of the impeller computed in step (4), according to the impeller inlet continuity equation 9 , is equal to $130 \mathrm{~mm}$. The corresponding $B / D_{1}$ ratio is equal to 0.18 , which is deemed to be feasible from a structural point of view. To select the optimal values of the blades number $N_{\mathrm{b}}$ and of the $D_{2} / D_{1}$ ratio a set of simulations was carried out by using the minimum value of the water discharge $Q_{\min }$, corresponding to the minimum impeller inlet angle $\lambda_{\min }$ :

$$
\lambda_{\min }=\frac{\lambda_{\max } \cdot Q_{\min }}{Q_{\max }}
$$


The inlet angle $\lambda_{\min }$, corresponding to the minimum discharge $Q_{\min }=0.260 \mathrm{~m}^{3} / \mathrm{s}$ (Fig. 13), is equal to $39.8^{\circ}$. The corresponding optimal blade geometry provides $N_{\mathrm{b}}=60$ and $D_{2} / D_{1}=$ 0.75. The blade and the circular segment thickness have been assumed equal to $4 \mathrm{~mm}$.

The characteristic curve of the designed turbine, assuming an automatic regulation of the control device, is an horizontal line $\left(H_{c}=H_{t}\right)$ for all the plotted discharge range, and would increase for larger values (when the inlet angle is the maximum possible one). The maximum efficiency is equal to 0.89 at $100 \%$ of $Q_{\max }$ and the minimum efficiency is equal to 0.83 at $28 \%$ of $Q_{\max }$; for the more frequent discharge $\left(Q_{m o d}\right)$ the efficiency is equal to 0.87 .

The optimal turbine produces a net yearly energy equal to 3,300 MWh with a minimum and maximum power respectively equal to $160 \mathrm{~kW}$ and $500 \mathrm{~kW}$. The economic value of the expected production is approximately $€ 650,000$, assuming a cost of energy purchased by the water manager equal to $0.2 € / \mathrm{kWh}$ (in Italy).

\section{DESIGN OF THE PROPOSED TURBINE IN CASE OF DOWNSTREAM DISCHARGE REGULATION}

The above described design procedure guarantees an inlet velocity norm close to its optimal value (about twice the reference system velocity) only if the hydraulic head $H$ is constant at the turbine upstream boundary, which is usually true when the pipe carrying the water is part of an hydroelectric plant.

On the other hand, if the pipe has been designed mainly for water transportation, its diameter is likely to be the minimum one needed to allow the maximum discharge planned along its life time, with an hydraulic head dissipation equal to the topographic jump, minus some extra length. This extra length is due to the size of the actual diameter, that exceeds the minimum required, as well as to some possible roughness deterioration inside the pipe along its future life time. Its dissipation, at the construction time, is accomplished by means of a 
pipe valve usually located at the end of the pipe, which is also used for discharge regulation.

Observe that only the hydraulic energy saved along the pipe, mainly during periods with discharge values lower than the maximum one, can be converted into electric energy. On the other hand, in this case the turbine can also be used for downstream discharge regulation and this avoids the need of installing a dedicated valve.

Also observe that using the previously presented regulation system, it is not possible to always satisfy the optimal relationship given by Eq. (8), because the hydraulic head $H$ changes, along with the velocity norm $V$ given by Eq. (5). The power $P$ that can be converted in electricity according to Eq. (3) is related to the discharge by the following identity:

$$
P=\gamma \cdot Q \cdot\left(H_{t}-K_{1} Q^{2}\right)
$$

The annual energy production is given by:

$$
E=\sum_{i=1}^{12}\left[\gamma \cdot \eta_{i}\left(V_{r}, \lambda\right) \cdot Q_{i} \cdot\left(H_{t}-K_{1} Q_{i}^{2}\right) \cdot \Delta t_{i}\right]
$$

where $\Delta t_{i}$ is the number of seconds per month.

In the following, based on the previous hydrodynamic analysis, the authors assume the efficiency $\eta$ to be function mainly of the inlet angle $\lambda$ and of the velocity ratio $V_{r}$, defined as the ratio between the tangent component of the particle velocity at the impeller inlet and the velocity of the reference system at the same point. This implies that the search of the optimum outer diameter $D_{\text {opt }}$ can be carried out according to the following procedure:

1) According to the known discharge duration curve of the plant, compute the modal discharge $Q_{\text {mod }}$, the corresponding turbine head $H_{\text {mod }}$ by Eq. (3) and the corresponding $D_{m o d}$ value by Eq. (8);

2) Select $\alpha, \lambda_{\max }, N_{\mathrm{b}}, D_{2} / D_{l}$ and $c_{i n}$ according to the previous methodology, assuming an $H=H_{\text {mod }}$ constant hydraulic head;

3) Compute by CFD simulations and plot the $\eta\left(V_{r}, \lambda\right)$ relationship for 
$V_{r}^{\min } \leq V_{r} \leq V_{r}^{\max }$ and $0<\lambda \leq 120^{\circ} . V_{r}^{\min }$ and $V_{r}^{\max }$ be computed by merging the continuity equation at the impeller inlet with the velocity-head relationship (Eq. (5)), to get:

$$
V_{r}^{\min }=\frac{2 c_{i n} \sqrt{2 g H_{\min }} \cos \alpha}{\omega D_{\max }}(13 \mathrm{a}), \quad V_{r}^{\max }=\frac{2 c_{i n} \sqrt{2 g H_{\max }} \cos \alpha}{\omega D_{\min }}(13 \mathrm{~b}),
$$

where $H_{\min }$ and $H_{\max }$ are the turbine head corresponding respectively to the maximum $Q_{\max }$ and the minimum $Q_{\min }$ discharge of the duration curve according to Eq. (3). To restrict the number of computational grids used in the simulations, for a set of inlet angle $\lambda$ a series of simulations can be run, using different head values and the same $D_{m o d}$ outer diameter. Head values greater and lower than the actual maximum and minimum ones can be used to explore the efficiency corresponding to very high or very low relative velocities. Observe in Fig. 15 the relationship $\eta\left(V_{r}, \lambda\right)$ obtained for the following case study.

4) Compute the optimum diameter that maximizes the objective function (Eq. (12)). To this aim, for each candidate diameter $D_{1}$ and rotational velocity $\omega$ (if more than one is available):

4.1) Compute the width $B$ corresponding to the maximum discharge $Q_{\max }$, according to the impeller inlet continuity equation (9) (with $H=H_{m i n}$ ).

4.2) For each value $Q$ of the discharge curve compute $\lambda$ and $V_{r}$ according to:

$$
\lambda=\frac{Q}{D_{1} \cdot B \cdot c_{i n} \sqrt{2 g H} \cdot \sin \alpha}(14 \mathrm{a}), \quad V_{r}=\frac{2 \cdot c_{i n} \sqrt{2 g H} \cdot \cos \alpha}{\omega \cdot D_{1}}(14 \mathrm{~b}),
$$

where $Q$ and $H$ are linked by Eq. (3). Estimate, from the chart of Fig. 15, the corresponding $\eta$ value. 
4.3) Estimate the objective function $E$ (Eq. (12)) by summing the contributions given by each different discharge value. Also in this case, before accepting the computed optimal diameter, it is necessary to check the feasibility of $B$, according to the limits suggested in step 4 of section "DESIGN OF THE PROPOSED TURBINE IN CASE OF DOWNSTREAM DISCHARGE REGULATION". A similar procedure can be carried out also for different candidate angular velocities, if different options are available.

5) Computed the minimum inlet angle $\lambda_{\min }$ corresponding to $B, Q_{\min }$ and $D_{\text {opt }}$ according to Eq. (14a) (where $H=H_{\max }$ ), and then optimize for $\lambda=\lambda_{\min }$ and $Q=Q_{\min }$ the blade parameters $N_{b}$ and $D_{2} / D_{l}$.

A flowchart representing the design procedure in case of downstream discharge regulations is reported in Fig. 16.

\section{APPLICATION TO A REAL SITE}

The following case study investigates the economic benefit of the replacement of a flow control valve with the proposed cross flow turbine in the outlet node of a water pipeline.

The pipeline, $10 \mathrm{~km}$ long, supplies fresh water to the drinking water plant of Palermo town (Italy), named "Risalaimi". The free surface of the lower tank is located at an altitude of $211.3 \mathrm{~m}$ a.m.s.l. and the upper reservoir, named "Cozzo Tondo" is located at an altitude of $244.0 \mathrm{~m}$ a.m.s.l. The tanks are connected by a cast-iron pipeline with diameter $800 \mathrm{~mm}$. A flow control valve is installed in the pipe, near the lower tank. The pipe head loss per unit discharge $K_{l}$ is equal to $47.92 \mathrm{~s}^{2} / \mathrm{m}^{5}$.

The upper reservoir is fed by a pumping station composed of four parallel pumps, with a nominal flow rate of $0.2 \mathrm{~m}^{3} / \mathrm{s}$ each. Even if the reservoir has some capacity, the water manager wants to maintain an almost constant water level and the entire pumped discharge has to be delivered to the lower tank. In order to do that, the flow in the downstream pipe is controlled by different opening degrees of the flow control valve that have to be 
automatically selected according to the measured trend of the upstream pressure. Fig. 17 shows the monthly mean flow distribution, measured in the year 2010, which can be assumed also unvaried in the following years. The peak demand attains in the original discharge hydrograph a maximum value of $0.700 \mathrm{~m}^{3} / \mathrm{s}$ and the modal value is equal to $0.620 \mathrm{~m}^{3} / \mathrm{s}$.

The procedure described in the paragraph 6 has been applied for the turbine design. In order to ensure the water demand even in exceptional conditions, the maximum discharge $Q_{\max }$ selected to be used in Eq. (9) is equal to $0.700 \mathrm{~m}^{3} / \mathrm{s}$. A design discharge $Q_{\text {mod }}=0.620$ $\mathrm{m}^{3} / \mathrm{s}$, equal to the modal value, and the corresponding values $H_{\text {mod }}=13.9 \mathrm{~m}$ and $D_{\text {mod }}=321$ mm have been selected (step 1). The following geometrical parameters were estimated, like in the case of constant hydraulic head (step 2): $\alpha=15^{\circ}, \lambda_{\max }=120^{\circ}, c_{i n}=0.8, N_{\mathrm{b}}=50$ and $D_{2} / D_{1}=0.70$. The circular segment thickness has been assumed equal to $5 \mathrm{~mm}$.

In order to compute the minimum and maximum velocity ratio in Eqs. 13a) and 13b), the following values have been selected for step 3): $D_{\min }=472 \mathrm{~mm}, D_{\max }=261 \mathrm{~mm}, \omega=400$ r.p.m.. By means of twenty-five 2D simulations of the CFX-ANSYS code, carried out using five possible mesh geometries, each one corresponding to a different $\lambda$ value, it was possible to draw the efficiency curves shown in Fig. 15. The optimization of the outer diameter and the rotational speed according to step 4) led to the following optimal values: $D_{\text {opt }}=390 \mathrm{~mm}$ and $\omega=300$ r.p.m.. The width $B$, according to Eq. (13), is equal to $616 \mathrm{~mm}$ and the $B / D_{1}$ ratio $=1.58$ is assumed to be feasible from the structural point of view. The blade parameters $N_{b}$ and $D_{2} / D_{1}$ are optimized according to step 5), to finally get $N_{b}=60$ and $D_{2} / D_{1}=0.75$. To confirm the original assumption $\eta=\eta\left(V_{r}, \lambda\right)$, three simulations have been carried out using three different $\lambda$ values and the efficiency obtained for each simulation has been superimposed on the efficiency curves of Fig. 15.

According to the discharge duration curve of the plant, the designed turbine produces a net energy equal to $630 \mathrm{MWh}$, with an average annual hydraulic efficiency equal to 0.84 and a 
minimum and maximum power respectively equal to $37.7 \mathrm{~kW}$ and $63.0 \mathrm{~kW}$. The economic value of the expected production is approximately $€ 160,000$, assuming a cost of energy purchased by the water manager equal to $0.2 € / \mathrm{kWh}$ (in Italy) for the upstream pumping station.

\section{CONCLUSIONS}

The paper has outlined a simple but rigorous procedure for the design of a cross-flow turbine with discharge regulator. The regulator brings the important benefit of transforming all the residual energy left at the turbine location and also avoids the need of installing other instruments in the case of downstream discharge regulation. The machine efficiency, for a large range of heads and discharges, attains values greater than $80 \%$, up to a maximum of almost $90 \%$. The low limit of the discharge, for fixed head value, is given by the need of avoiding the 3D effects of too small impeller widths (below 3-4 cm), as well as too small inlet angles (below $30^{\circ}$ ). The construction and the management costs of the head regulation system, including automation, are very low (no more that $1 € / \mathrm{W}$ ), because it can be based on the use of simple pressure sensors. In the case of negligible energy losses along the pipe, and no downstream discharge regulation, the head regulation system will open the inlet angle when the pressure rises above a maximum value and will close it when the same pressure drops below a minimum value (where the maximum has to be strictly greater than the minimum to avoid a continuous movement of the circular profiled segment).

\section{ACKNOWLEDGEMENTS}

The research has been supported by "Hydroenergy" project, P.O. F.E.S.R. 2007-2013, Sicily. 


\section{NOTATION}

The following symbols are used in this paper:

$q=$ specific discharge;

$c_{i n}=$ velocity coefficient of the nozzle;

$B$ = impeller width;

$D_{1}=$ outer impeller diameter;

$D_{2}=$ inner impeller diameter;

$D_{\text {mod }}=$ outer impeller diameter, corresponding to the modal discharge;

$D_{\text {opt }}=$ optimum outer impeller diameter;

$E=$ annual energy production;

$E_{\Delta t}^{c}=$ energy that the current transfers to the single channel of the impeller during the interval $\Delta t$;

$H=$ hydraulic head;

$H_{c}=$ hydraulic head immediately upstream the turbine;

$H_{c, \mathrm{o}}=$ hydraulic head at the turbine outlet;

$H_{t}=$ topographic jump between the inlet location and the turbine axis;

$K_{l}=$ frictional head losses coefficient;

$N_{b}=$ number of blades;

$P_{\text {nom }}=$ nominal power;

$P_{\text {out }}=$ output power;

$Q=$ discharge;

$Q_{c}=$ discharge entering and leaving the single channel of the impeller;

$Q_{\max }=$ maximum discharge;

$Q_{\min }=$ minimum discharge;

$Q_{\text {mod }}=$ modal discharge; 
$\underline{U_{1}}=$ velocity of the rotating reference system at the inlet section;

$\underline{U_{2}}=$ velocity of the rotating reference system at the outlet section;

$U_{F}=$ velocity of the rotating reference system at the final section of the stream tube;

$\underline{U_{I}}=$ velocity of the rotating reference system at the initial section of the stream tube;

$V=$ norm of the inlet velocity;

$\underline{V_{1}}=$ velocity of the particles entering the single channel of the impeller;

$\underline{V_{2}}=$ velocity of the particles leaving the single channel of the impeller;

$V_{F}=$ velocity of the particle at the final section of the stream tube;

$\underline{V_{I}}=$ velocity of the particle at the initial section of the stream tube;

$V_{\text {opt }}=$ optimal inlet velocity;

$V_{r}=$ velocity ratio;

$\alpha=$ angle between the particle velocity and the tangent direction at the impeller inlet;

$\beta_{F}=$ angle formed by the vectors $\underline{V_{F}}$ and $\underline{U_{F}}$

$\beta_{I}=$ angle formed by the vectors $\underline{V_{I}}$ and $\underline{U_{I}}$

$\Delta L=$ blade distance measured along the inlet arc;

$\Delta t=$ time interval;

$\gamma=$ water specific weight;

$\eta=$ efficiency;

$\eta_{\max }=$ maximum efficiency value;

$\eta_{\mathrm{t}}=$ total efficiency;

$\lambda=$ angle of the arc available for the discharge inlet along the impeller outer circumference; 
$\lambda_{\max }=$ angle of the arc available for the maximum discharge inlet along the impeller outer circumference;

$\lambda_{\min }=$ angle of the arc available for the minimum discharge inlet along the impeller outer circumference;

$\lambda_{\text {mod }}=$ angle of the arc available for the modal discharge inlet along the impeller outer circumference;

$\rho=$ water density;

$\omega=$ impeller angular velocity

\section{REFERENCES}

Carravetta A., del Giudice G., Fecarotta O., Ramos H. (2012). "Energy production in water distribution networks: A pat design strategy." Water resources management 26(13): 39473959. doi:10.1007/s11269-012-0114-1;

Carravetta A., del Giudice G., Fecarotta O., Ramos H. (2013). "PAT Design Strategy for Energy Recovery in Water Distribution Networks by Electrical Regulation." Energies 6(1), 411-424; doi:10.3390/en6010411;

Carravetta A., Fecarotta O., Sinagra M., Tucciarelli T. (2014). "Cost-Benefit Analysis for Hydropower Production in Water Distribution Networks by a Pump as Turbine." J. Water Resour. Plann. Manage., 140(6); doi: http://dx.doi.org/10.1061/(ASCE)WR.19435452.0000384;

Carravetta A., Giugni M. (2006). "Functionality factors in the management and rehabilitation of water networks. Management of water networks." Proceedings of the Conference «Efficient Management of Water Networks. Design and Rehabilitation Tech-niques», Ferrara, May 2006, 40-56;

Costa Pereira N.H., Borges J.E. (1996). "Study of the nozzle flow in a cross-flow turbine." 
International Journal of Mechanical Sciences 38(3): 283-302;

Haurissa J., Wahyudi S., Irawan Y.S., Soenoko R. (2012). "The Cross Flow Turbine Behavior towards the Turbine Rotation Quality, Efficiency, and Generated Power." Journal of Applied Sciences Research 8(1): 448-453;

Joshi S., Gordon A., Holloway L., Chang L., Kojabadi H.M. (2005). "Development of a Stand Alone Micro-Hydro System using Pump as Turbine Technology for Low Head Sites in Remote Areas." Proceedings of the 20th Power System Conference, Tehran - Iran, 2005;

Kaniecki M. (2002). "Modernization of the out flow system of cross-flow turbines." Task Quarterly 6, 4: 601-608;

Khosrowpanah S., Albertson M.L., Fiuzat A.A. (1984). "Historical overview of cross flow turbine." Water Power \& Dam Construction 36(10): 38-43;

Kokubu K., Son S.W., Kanemoto T., Choi Y.D. (2011). "Internal flow analysis on a micro cross-flow type hydro turbine at very low specific speed range." Proceedings 11th Asian International Conference on Fluid Machinery and the 3rd Fluid Power Technology Exhibition, IIT Madras, Chennai, India, November 2011;

Khurana S., Kumar A. (2011). "Small Hydro Power - A review."International Journal of Thermal Technologies Vol.1, No.1.

Paish O. (2002). "Small hydro power: technology and current status." Renewable and Sustainable Energy Reviews 6: 537-556;

Ramuz D., Cama M., Sebeloue M., Tamarin O., Roubaud F., Clergeot H., Kauffmann J.M. (2005). "Modelling and Simulation of a Doubly Fed Induction Generator in stand-alone Variable Speed Hydro Turbine." Proceedings of the European Conference on Power Electronics and Applications, EPE - Dresden;

Sammartano V., Aricò C., Carravetta A., Fecarotta O., Tucciarelli T. (2013). "Banki-Michell Optimal Design by Computational Fluid Dynamics Testing and Hydrodynamic Analysis." 
Energies 6(5): 2362-2385;

Singh D. (2009). "Resource assessment handbook." Asian and Pacific centre for transfer of technology of the United Nations - Economic and Social Commission for Asia and the Pacific (ESCAP), 16-34.

Verhaart P. (1983). "Blade calculations for water turbines of the Banki type." Eindhoven University of Technology Report WPS3-83.03.R351.

Zimny J., Michalak P., Bielik S., Szczotka K. (2013). Directions in development of hydropower in the world, in Europe and Poland in the period 1995-2011. Renewable and Sustainable Energy Reviews, Volume 21, pp. 117-130. doi.org/10.1016/j.rser.2012.12.049 


\section{LIST OF FIGURES}

Fig. 1 Turbine installed at an aqueduct end.

Fig. 2 Characteristic and efficiency curves for a generic turbine.

Fig. 3 Relative efficiencies regarding the discharges for Kaplan, Pelton, Francis, Cross flow, Propeller turbine and PAT.

Fig. 4 Hydraulic Flap in an Ossberger cross-flow turbine.

Fig. 5 Section of the cross-flow with the Cink control device.

Fig. 6 a) larger angle $\beta_{I}$ between $\underline{V}_{\underline{I}}$ and $\underline{U}_{\underline{I}}$; b) smaller angle $\beta_{F}$ between $\underline{V}_{\underline{F}}$ and $\underline{U}_{\underline{F}}$.

Fig. 7 Mesh of the computational domain and a zoomed view close to a blade of the impeller.

Fig. 8 Vertical section and a plane view of the cross-flow turbine.

Fig. 9 Plots of the sensitivity analyses with $Q_{\min }$ : a) efficiency $\eta$ as a function of the number of blades $N_{b}$; b) efficiency $\eta$ as a function of the $\mathrm{D}_{2} / \mathrm{D}_{1}$ ratio.

Fig. 10 Efficiency $\eta$ and $\lambda$ curves of the designed turbine.

Fig. 11 Plots of the sensitivity analyses with $Q_{m o d}$ : a) efficiency $\eta$ as a function of the number of blades $N_{b}$; b) efficiency $\eta$ as a function of the $\mathrm{D}_{2} / \mathrm{D}_{1}$ ratio.

Fig. 12 Efficiency curves of the impellers designed for $\lambda_{\text {min }}$ and $\lambda_{\text {mod. }}$

Fig. 13 Flow chart of the design procedure in case of negligible energy losses.

Fig. 14 Monthly mean flows at the year 2010.

Fig. 15 Efficiency curves $\eta=\eta\left(V_{r}, \lambda\right)$ for the prediction turbine for the below case study.

Fig. 16 Flow chart of the design procedure in case of downstream discharge regulations.

Fig. 17 Monthly mean flows at the year 2010. 